\title{
ENTRE MORADAS, RUAS E ESTÓRIAS: ENSAIO ETNOGRÁFICO SOBRE RUPTURA, MEMÓRIA DO TRABALHO E ITINERÁRIOS URBANOS EM UMA VILA OPERÁRIA NA CIDADE DE PORTO ALEGRE ${ }^{1}$.
}

\author{
Rafael Martins Lopo ${ }^{2}$
}

\section{Introdução}

A cidade, em toda sua complexidade, abriga uma série de indagações caríssimas a Antropologia Contemporânea. Desde o crescimento de núcleos urbano-industriais, e a constante migração de indivíduos para a cidade, a disciplina antropológica tem se colocado a disposição para se perguntar sobre estes movimentos ${ }^{3}$.

A proposta deste artigo tem como base a discussão acerca dos temas da memória coletiva e das formas de sociabilidade no mundo urbano contemporâneo, sobre a ótica da Antropologia das Sociedades Complexas.

Mas, o que pode ser pensado como sociedade complexa? As reflexões neste sentido apontam sempre para uma valorização do indíviduo, de suas formas de sociabilidade, e para a maneira como estes interagem com o espaço em que vivem e como o representam ${ }^{4}$. O desafio, neste sentido, é sempre pensar nestas individualidades e nestes agenciamentos entre projetos individuais e ações coletivas. Segundo Gilberto Velho (2004), a cidade abriga uma complexa gama de "visões de mundo" e "campos de significados". Inspirado em Schultz, este autor nos aponta que é através da dinâmica e das escolhas que se fazem diante destes diferentes campos de possibilidade que podemos identificar a tecitura e as bases fundamentais do indivíduo moderno. Estar na cidade é, a todo o momento, fazer escolhas, alocar um projeto individual dialogando com um projeto coletivo, que reflete as preocupações e sentidos de um campo de significado.

\footnotetext{
1 Artigo apresentado como parte integrante do processo de avaliação da disciplina Indibidualismo, Sociabilidade e Memória, ministrada pelas professoras Ana Luiza Carvalho da Rocha e Cornelia Eckert, no $1^{\circ}$ semestre do ano de 2010, no Programa de Pós-Graduação da Universidade Federal do Rio Grande do Sul.

${ }^{2}$ Universidade Federal do Rio Grande do Sul, Brasil.

${ }^{3}$ Como referência no Brasil, temos alguns dos "pais fundadores" da Antropologia Urbana. Ver Eunice Dhuran (1978), Ruth Cardoso (1986), Ruben Oliven (1980), entre outros.

${ }^{4}$ Para tal, os trabalhos que seguem a linha de Louis Dummont sobre individualismono Brasil acrescentam e problematizam a noção de indivíduo proposta por este autor. Como exemplo, podemos aqui citar Gilberto Velho (2004), Luis Fernando Dias Duarte (1986), e Tania Salem (1997). De uma forma ou de outra, a preocupação é sempre olhar para a teoria do individualismo sobre a ótica de uma realidade diferente e diversa como a brasileira.
} 
As questões propostas pelo autor também enriquecem as reflexões acerca do trabalho nas sociedades complexas. Sobre isto, a defesa do autor, inspirada em Simmel e nos estudos da escola de Chicado, é que é somente na cidade que estas individualidades são chamadas a interagir. É através de uma divisão social do trabalho históricamente bem demarcada, que podemos identificar a cidade como um espaço de problemas caros aos indivíduos e suas coletividades.

Para o tema aqui proposto, é preciso ir além. É preciso, acrescentar à esta esteira de estudos clássicos, questões acerca do tempo e da memória, como estes são refletidos na narrativa de seus moradores e como a cidade acolhe e participa destas práticas. Para não entrar em um estudo propriamente histórico, o desafio é sempre considerar o próprio trabalho antropológico como uma narrativa, e se reconhecer como um dos múltiplos narradores sobre a memória da cidade. Cabe salientar que há aqui, uma continuidade, e uma forte influência de trabalhos já consagrados na área, advindos de uma linha de pesquisa de mais de 10 anos no Banco de Imagens e Efeitos Visuais. Conforme o trabalho de Ana Luiza Carvalho da Rocha e Cornelia Eckert (2004), uma nova arte de narrar se configura a partir da exeperiência vivida no mundo urbanocontemporâneo, onde o antropólogo também é visto como um narrador privilegiado das dinâmicas e transformações que ocorrem na cidade. Ao compartilhar uma série de códigos em diferentes campos de significados, o antropólogo não somente narra a vida ou a experiência do outro, mas também o processo de estranhamento e familiarização com a sua própria cidade. Tendo em vista isto, o processo de escrita e produção de conhecimento antropológico vira um espaço privilegiado para uma nova arte de narrar.

Para tanto tentarei neste artigo entender como a entrada em campo e o trabalho específico desenvolvido no Banco de Imagens e Efeitos Visuais ${ }^{5}$, sob a orientação de Cornélia Eckert e Ana Luiza Carvalho da Rocha, pode colaborar na análise de uma situação específica na cidade de Porto Alegre - a construção da Vila do IAPI - e sua condição no presente. Esta região da cidade de Porto Alegre é fruto de um projeto de habitação operária na era do Governo Getúlio Vargas, e objeto de políticas de patrimônio na pauta pública das prefeituras recentes (SMPM, 1994.).

Atualmente, o Banco de Imagens e Efeitos Visuais tem como iniciativa principal de pesquisa o projeto "Trabalho e Cidade: Antropologia da memória do trabalho na

\footnotetext{
${ }^{5}$ O BIEV, ligado ao Laboratório de Antropologia Visual da UFRGS, é um núcleo de pesquisa que agrega diferentes pesquisadores de diferentes níveis e formação acadêmica para pensar discussões sobre o acervo, digitalização e produção de imagens, sempre preocupado teoricamente com os temas da memória coletiva, itinerários urbanos, formas de sociabilidade e crise nas sociedades complexas.
} 
cidade moderno-contemporânea". Inserida neste contexto, e de certa forma, por estar repensando meu campo de pesquisa devido ao ingresso no mestrado em Antropologia Social da UFRGS, minha pesquisa acabou aderindo a esta linha de questões. De uma forma mais particular, o que pretendo salientar aqui, é como é possível re-pensar a relação entre o projeto de cidade-jardim proposto para o IAPI e as práticas cotidianas de seus habitantes, através dos temas da memória e formas de sociabilidade. Minha entrada no bairro se deu através do trabalho constante de ida a campo. Ainda de maneira iniciática, no segundo semestre de 2010, caminhei e percorri as ruas do bairro durante os Sábados para tentar identificar algumas de suas feições e suas características principais.

Além de ressaltar uma memória agenciada nas narrativas e nas práticas cotidianas destes moradores, é preciso reconhecer a ruptura, como nos ensina Bachelard (1988), como fundamental neste processo. Reconhecer uma rítmica do tempo e da experiência vivida em múltiplas camadas de tempo pode ajudar a reconhecer uma nova maneira de olhar para o bairro, relacionando as transformações da cidade, das práticas e relações de trabalho, e das práticas cotidianas dos moradores locais. Devido a isto, o objetivo específico deste artigo é identificar o IAPI como uma ruptura não só na tipologia arquitetônica da época, mas como uma ruptura nas idéias de bairro ou habitação vigentes na época de seu surgimento. Se reconhecermos que as práticas e relações de trabalho mudam com o tempo e com a constante transformação industrial e fabril da cidade, é preciso entender que as formas de sociabilidade, de ocupação de espaço, morada, e narrativas também se deslocam em camadas de sentido.

Além disto, é somente ao reconhecer a riqueza destas rupturas que podemos entender as mesmas no tempo presente, sem correr o risco de endurecer a memória do bairro em políticas de patrimônio e patrimonialização do espaço vivido destes moradores. A idéia é muito mais trazer um diálogo e estabelecer um olhar outro para a memória coletiva da cidade do que propriamente desvalorizar as políticas atuais. A contribuição, neste sentido, caminha na direção do reconhecimento da Antropologia, e mais especificamente da etnografia da duração (Eckert e Rocha, 2005), enquanto espaço de problemas, como instrumento primordial para entender e refletir sobre a memória coletiva de um local específico da cidade de Porto Alegre.

O objetivo final deste artigo é, portanto, problematizar o que significa e como podemos avaliar a idéia de "organicidade" proposta pelo projeto arquitetonico incial da vila do IAPI. A partir disto, e para enriquecer o debate através de questões da 
antropologia, é preciso pensar como, nas práticas cotidianas e nas narrativas de alguns moradores, podemos re-avaliar estas noções entre interior e exterior, público e privado, casa e rua, tão caras a antropologia e às ciências humanas de maneira geral.

\section{O que é o IAPI?}

Pensar o próprio projeto de bairro ou unidade de vizinhança em suas diferentes dimensões pode nos ajudar a identificar algumas características importantes para se falar de do IAPI e sua relacao com uma memória do trabalho na cidade de Porto Alegre.

O IAPI está situado na Zona Norte da cidade de Porto Alegre, no bairro Passo d'Areia, constituido por cerca de 2.446 moradias. Conhecido antigamente como Chácara dos Pires, a região, após a enchente de 1941, foi tomada por fábricas e indústrias da cidade. Barbosa (2008) cita algumas destas avenidas, como a Voluntários da Pátria, Benjamim Constant e Cristóvão Colombo. Duas dessas, ao lado da Assis Brasil, formam uma complexa malha viária que envolve o IAPI e seus limites, e a região integra-se hoje a malha urbana da cidade inserida em um dos principais eixos de expansão dos bairros de classe média e alta, como o bairro Carlos Gomes e Três Figueiras.

Segundo Cleusa Terezinha Silva (1999), a preocupação com a moradia popular também se apresenta no Brasil de forma evidente no Brasil. A partir da década de 1930, o país estava em um acelerado processo de desenvolvimento industrial e econômico e se fazia necessário uma política que atendesse a falta de habitação popular. $O$ então presidente Getúlio Vargas encontra nos conjuntos habitacionais uma das soluções para este problema, que vinha desde a República Velha (1889-1930), e resulta na execução de vários projetos de construção nesta área, beneficiando as classes populares, priorizando o operariado urbano que estava em franca ascensão. (Silva, 1999: 135)

Por isso, é importante salientar a condição particular em que a cidade de Porto Alegre e a expansão das áreas industriais se encontrava na época em que o bairro foi planejado. Além da crescente industrialização que ocorria no país na década de 50 , surgia a necessidade de se criar moradias e espaços de lazer para os empregados destas novas indústrias.

No inicio do governo de Vargas foram criados Institutos, e ocorre, assim, um processo de transformação e ampliação das Caixas de Aposentadorias e Pensão (CAPs) - institutos primeiramente na década de 1920. Os Institutos eram baseados em categorias profissionais amplas e sua administração não ficava a cargo de empregados e 
patrões, como no caso dos CAPs, e sim a encargo do governo como parte integrante do sistema. Os IAPs eram vinculados ao Ministério do Trabalho e tinha por função atender o sistema previdenciário, procurando também soluções para o problema de moradia popular. (Silva, 1999: 135). Segundo o relatório da Secretaria do Planejamento Municipal feito em 1994 (SMPM, 1994), a criação dos Institutos de Aposentadorias e Pensões se deu no ano de 1934, e em 1937, já reunia cerca de 844.400 associados. Abaixo, podemos ver um trecho coletado do Trabalho do dia do arquiteto feito pelo Assistente Administrativo Ruy da Costa Mendes, publicado no dia 5-12-52, em homenagem à Décima semana oficial do Engenheiro e do Arquiteto.

A construção de casas populares é -acreditamos nós- a melhor política para aumentar a produção nacional. Todavia, o fator primordial da nossa economia é o homem. Devemos, pois, preservar esse elemento básico, proporcionando lares confortáveis em todas as cidades.

Construindo, pois, a Vila dos Industriários, onde ficarão higienicamente instaladas mais de 15.000 pessoas, cumpre o Instituto dos Industriários com uma de suas mais elevadas finalidades (se bem que não tivesse aqui obrigação específica) $e$ com esse feito de tão extraordinária envergadura, assiste a sociedade, com visível emoção ao lançamento no Passo d'Areia do marco inicial de uma nova era que, sob a sua influência do melhor nível de vida, garantirá, por certo, uma forma de intensa reação do organismo social. $(p .8)^{6}$

Foi nesse contexo que o IAPI (Instituto de Auxilio a Previência Industriária) resolveu investir na construção de uma vila operária. Com o projeto incial do eng. Eduardo Gardolinski, e o projeto urbanistico do eng. Marcos Kruter (Souza, 2004), a proposta inicial apoiava-se na idéia de cidade-jardim, que privilegia o traçado orgânico, o uso intensivo de áreas verdes e sua integração com as edificações. O IAPI manteve por anos suas caracteristicas iniciais, protegido por um sistema de apropriação dos imóveis como valor de uso, onde o poder público detinha a efetiva propriedade ${ }^{7}$. Desde o final da década de 60, os moradores já são donos de suas propriedades, e o processo de venda e aluguel no bairro é constante desde o período em questão. Mais abaixo, tentarei tensionar e trazer isto dentro das preocupações levantadas por este artigo.

No entanto, o que podemos chamar de cidade-jardim? No relatório da Prefeitura de Porto Alegre, já citado anteriormente, a cidade jardim é vista como um lugar aprazível, com construções de qualidade. Há o uso intenso da vegetação,

\footnotetext{
${ }^{6}$ Trecho coletado do acervo do Museu Municipal Moyses Velinho, em Porto Alegre, RS.

${ }^{7}$ A idéia de se construir a vila operária existia desde 1942 e só seria concluida em 1954, com uma área em torno de 66ha. Em seu projeto inicial eram planejadas 1961 residências, e somente depois foram construídas no total 2456 unidades de habitação. Outros equipamentos públicos também foram incluidos no programa, como o Parque Alim Pedro, dois colégios e a abertura de duas grandes avenidas no bairro.
} 
arborização, utilização e criação de praças e parques, além de um traçado orgânico entre o sistema viário, os prédios, edifícios em meio a jardins, rementendo ao marco inicial do projeto do inglês Edebenezer Howard. No final do século XIX, o engenheiro trazia como princípio a integração cidade-campo, numa tentativa de criar uma unidade autosuficiente. Havia neste primeiro projeto, que foi repetido em Porto Alegre, uma tentativa de evitar a especulação imobiliária, através de um sistema de propriedade coletiva do solo e propriedade privada das construções e dos meios de produção. Dentre as características principais do projeto, estão: o uso de baixas densidades; hierarquia do sistema viário, com traçado orgânico; acesso a moradias através de ruas de mão única ou sem saída; acessibilidade ao interior das quadras, através de vias pedestres, assim como construções descoladas dos limites do lote, deixando recuos de frente, laterais e de fundos para jardins, hortas ou gramados. No caso do IAPI, além destes recursos, foram implantados, aproveitando a área acidentada e verde da região, um parque poliesportivo, chamado de Alim Pedro, algumas escolas, equipamentos públicos diversos, uma Igreja e diversos outros serviços.

No Brasil os primeiros "Jardins" foram construídos para a classe alta. Em Porto Alegre começaram a se construir loteamentos com características de cidade-jardim, como na Vila Conceição, Vila Assunção, entre outras. A diferença do IAPI, neste caso, é que o bairro concentra essas características de cidade-jardim e é, ao mesmo tempo, uma iniciativa do setor público. Em Porto Alegre, a Vila do IAPI foi construída pelo governo federal com esses recursos, para atender parte desta carência habitacional, mas neste caso específico, as unidades destinavam-se aos operários das indústrias que estavam estabelecidas ou se estabelecendo na zona norte da cidade.

Neste sistema de aplicação de recursos, segundo Marion Kruze (1991: 33), os moradores eram donos do valor de uso da propriedade e, portanto pagavam aluguel e o Instituto era o proprietário de fato do conjunto. O que vem a se modificar a partir da nova legislação sobre política habitacional e com a criação do Banco Nacional de Habitação (BNH), pela Lei n ${ }^{\circ} 4380$ de 21.08.64. Com essa nova política os IAP's não mais atuariam nas operações imobiliárias e os imóveis passariam a ser vendidos aos seus moradores. Constavam nas disposições gerais da mesma as seguintes medidas:

a- As carteiras imobiliárias dos Institutos de Aposentadoria e Pensões não poderiam mais, a partir da data da promulgação da Lei, iniciar novas operações imobiliárias, passando seus segurados a ser atendidos pelo novo sistema; 
b- Os Institutos de Aposentadorias e Pensões deveriam no prazo de doze meses efetuar a venda de seus conjuntos e unidades residenciais, ficando deste modo extinto o sistema de locação das habitações praticado por aquelas Instituições.

(Nunes, 1991, p.33)

Através do trabalho de campo, pude encontrar na narrativa de alguns antigos moradores falas semelhante àquelas expressas no livro publicado pela Prefeitura acerca da memória dos bairros (Nunes, 1991), com informações sobre o primeiro meio de transporte público na região, os jogos no parque Alim Pedro, e as dificuldades enfretadas por moradores referentes aos pagamentos das mensalidades. Neste sentido, o que se configura e se apresenta como problema de pesquisa para a pesquisa antropológica é adentrar em um espaço tão complexo e heterogêneo como o bairro sem adotar uma fala que ignore estas narrativas sobre as práticas de trabalho e sociabilidade destes moradores e habitués.

A condição de um bairro, vila ou zona é fundamental para representar um espaço ainda pouco conhecido, e já tem como princípio de concepção uma ruptura no tempo da cidade. Ao ser planejado como bairro operário nos moldes da cidade-jardim européia, o IAPI se estabelece como o único caso deste no Brasil financiado a partir da inciativa pública. A partir daí, é possível pensar a condição de uma memória que não é alusiva a uma "verdade história" ou a um único discurso da memória da cidade. Este é talvez, o primeiro grande desafio para o diálogo com alguns interlocutores em campo. Minha recente aproximacao a um antigo morador e trabalhador do bairro, me chamou atenção sobre isso: é possível que estes interlocutores tentem sempre me falar de um lugar "oficial" da memória do bairro, tentando me dar com exatidão algumas informações e deixando de lado os seus próprios conflitos e tensões cotidianas. Por isso, é preciso reconhecer que as discursividades e idéias de um "campo de significados" (Velho, 2004) ligado ao patrimônio também faz parte das questões centrais na vida destes atores sociais.

\section{Entrando em campo: sobre a fala de passos perdidos na Vila do IAPI}

Antes de qualquer evidência direta, é preciso adentrar no IAPI e tentar identificar algumas formas de ocupação do espaço, de interação e sociabilidade, ao mesmo tempo em que é importante para o pesquisador se perguntar se é possível mapear estes diferentes "campos de significados" (Velho, 2004) que configuram uma das principais características das sociedades complexas urbano-contemporâneas. 
Nesse sentido, a contribuição da prática de "etnografia de rua", proposta por Eckert e Rocha (2003) foi motriz para identificação de alguns espaços do bairro e a interação dos seus "habitués" com o local. Partindo da idéia de um percurso e de uma "fala de passos perdidos" (DeCerteau, 1994), pude adentrar nas vielas, ruas e pequenas vias que fazem do IAPI um local específico. Olhar para este espaço da cidade tentando me situar como um narrador do local, e sempre imbricado em uma cultura urbana particular, permitiu a este aprendiz-de-antropólogo compartilhar destas falas e começar a narrar a cidade pelas estórias do IAPI.

Os blocos de concreto misturados a algumas pequenas casas são muito diversos. Todo com cores opacas é verdade, mas cada um com uma característica diferente. Entre as variações, estão o número de andares (de 1 a 4), a cor do prédio (amarelo, cinza, marrom, havana), o número de janelas, o tipo de entradas e portas, a existência ou não de calçadas, entre outros. Há um arranjo muito rico, uma potência de boas imagens imensa, assim como são longíncuos os limites do bairro. O IAPI, para quem o vê de dentro pela primeira vez, é realmente muito grande. Por fora, parecem apenas prédios iguais, e sem ninguém dentro. Minha impressão primeira é completamente diferente. As ruas e vias se multiplicam em pequenas garagens, puxadinhos, lajes e re-apropriações do espaço. Há também uma delegacia, dois colégios, muitos estabelecimentos comerciais de diversos tamanhos, e muitas pessoas dentro das casas. (Diário de campo dia 13 de agosto de 2010.)

Após começar esta jornada etnográfica, que ainda perdurou por mais alguns meses, conheci seu Lino. Lino é um padeiro antigo da região, mas não mora no local. Interessante pensar, que atrás de antigos moradores, acabei me deparando com um interlocutor privilegiado que não mora, mas trabalha no local.

Meu primeiro contato com Lino se deu no dia 20 de agosto, em minha segunda saída de campo. Seu Lino é um senhor de cerca de 60 anos, de cabelos brancos e barriga avantajada. Ao falar, mistura a letra "r" com a letra "g", e sempre me aponta para os possíveis caminhos do trabalho e da rede social em que está inserido. Segundo me conta, foi para o IAPI com seu pai, quando este comprou a padaria no prédio de entrada do bairro, mudando-se posteriormente para o final da Avenida dos Industriários, mais próximo a Avenida Plínio Brasil Milano.

Como outros tantos moradores do local, seu Lino é um defensor fervoroso de Getúlio, e a todo o momento se lembras das benfeitorias feita pelo antigo presidente para o IAPI. Segundo ele, o bairro foi um modelo para os outros BNHs do Brasil, e até hoje possui a particularidade de ser um bairro com construções fortes e "gente do bem". Fora isto, é possível se indagar sobre este modelo de habitação popular proposto por Getúlio. É no mesmo espaço, projetado para ser um prédio comercial, que há mais de 50 
anos Lino recebe e atende clientes diversos. De homens a mulheres, jovens e velhos, amigos e vizinhos, entre tantos:

Eu conheço isso aqui há mais de 50 anos, quando vim pra ca trabalhar com meu pai e meu irmão. Cheguei aqui há 53 anos, no dia $1^{\circ}$ de agosto de 1963, e meu pai se chamava Laudelo Alves Martins.

A primeira vista, seu Lino parece ser aqueles interlocutores "sabe-tudo", que falam exatamente o que acham que o pesquisador procura, e não da muito espaço para dúvidas. Ao explicar que gostaria de ouvir histórias e coisas dele sobre sua experiência no bairro, a resposta confirma a primeira impressão:

Bem, eu posso te falar de 3 "livros" que eu "escrevi" com a vida. O primeiro, é sobre o que é uma padaria, que tem mais de 1200 páginas. O segundo é sobre minhas peripércias atrás do time do Internacional". O terceiro, é sobre "O Casamento", essa instutição sacana inventada pela sociedade cristã (Diário de campo dia 20 de agosto de 2010)

O projeto individual do pai de Lino não só foi influenciado por uma possibilidade de trabalho no local, como também influenciou as escolhas do filho, que acabou se tornando padeiro. Em minhas últimas saídas de campo, pude perceber como há um projeto coletivo de habitação nacional dialogando com as escolhas individuais. Como exemplo rápido, lanço mão de um trecho de diário em que conheci outra antiga moradora, dona Manoela, moradora do bairro há mais de 50 anos:

No meio da conversa, escuto o grito do seu Lino, me chamando para conhecer dona Manoela. Ela é uma das muitas clientes que seu Lino me fala para entrevistar. Dona Manoela veio para o bairro dia $1^{\circ}$ de novembro de 1952 uma semana antes de dar a luz ao seu primeiro filho. O segundo filho, como conta, se envolveu em um acidente de carro e faleceu. O filho mais velho já casou e saiu do IAPI, mas acabou voltando.

Manoela também me conta que antigamente o IAPI só tinha uma igrejinha pequena, 1 armazem, que a Plínio era a Estrada da Pedreira, estreita, e que o único açougue da região era na entrada. NO meio da conversa, seu Lino descobre que o açougue comprado pelo seu pai, na chegada ao bairro, era do tio de dona Manoela. (Diário de campo dia 18 de setembro de 2010)

Mesmo não citado acima, Manoela foi para o bairro quando o marido, que trabalhava na fábrica das tintas Renner, se cadastrou para ter direito a uma moradia no IAPI. Parece óbvio, mas é somente a partir de um projeto de construção de um bairro de habitação operária, que estes projetos individuais se cruzam e se entrelaçam para narrar um espaço vivido cotidianamente e coletivamente.

\footnotetext{
${ }^{8}$ Eu to começando a enjoar de ouvir falar tanto em futebol. Mentira minha. Ainda voltarei milhões de vezes a campo para escutar somente estas histórias...
} 
Essa problemática está presente nas biografias e trajetórias individuais. Os indivíduos modernos nascem e vivem dentro de culturas e tradições particulares, como seus antepassados de todas as épocas e áreas geográficas. Mas, de um modo inédito, estão expostos, são afetados e vivenciam sistemas de valores diferenciados $e$ heterogêneos. Existe uma mobilidade material e simbólica sem precedentes em sua escala e extensão. (Velho, 1994, p. 39)

O projeto individual de Manoela, assim como de muitos outros moradores, adentra em uma política pública de habitação popular que pensa a cidade de uma maneira alternativa às idéias vigentes. Porém, é possível que exista alguma relação mais direta entre estes diferentes projetos? Colocando a pergunta de outra forma, é possível reconhecer alguma relação entre as idéias de organicidade, de laços entre o público e o privado, entre a casa e a rua, do projeto do IAPI com a atual condição dos moradores do local?

Se pensarmos a cidade-jardim como um projeto maior, dentro de uma proposta arquitetônica inovadora, podemos identificar algumas rupturas e elementos importantes para problematizar a dialética entre espaço público e espaço privado, entre casa e rua; em termos bachelardianos, é possível ir além, e pensar uma dialética do interior e exterior, rompendo com uma visão progressista e única do passado glorioso ligado ao trabalho na cidade de Porto Alegre.

\section{A cidade-jardim e a cidade: questões acerca da morada como um local de memória:}

Como citado anteriormente, a vila do IAPI é um projeto elaborado pelo poder público, com influências diretas e claras das cidades-jardim européias. A proposta é clara, e não deixa dúvidas quanto aos seus objetivos, mas é possível, partindo de uma análise arquitetônica, problematizar de que maneira podemos entender essas lógicas dentro de uma análise da memória e da duração.

Influenciado por Bachelard, e pela orientação do BIEV, tomo aqui a memória como um ponto crucial na experiência vivida pelo sujeito no mundo. As lacunas, rupturas e o "nada" são fundamentais para se elaborar e entender uma ritmica do ser no mundo, o sujeito pleno, aquele que vive e que lembra. A duração, segundo o

\footnotetext{
${ }^{9} \mathrm{O}$ "nada" para Bachelard é tomado como um espaço de descontinuidades do instante. É neste sentido que a união entre a teoria de Roupnel - em que o instante é tido como única forma de apreensão e existência do real - e de Bergson - que considera que somente o tempo presente é capaz de mobilizar passado e futuro é fecunda para pensar a duração. Se em Bergson o nada não tem valor, é somente ao reconhece que há um ritmo lacunar e ondulatório constituído por instantes que Bachelard corrobora a idéia de uma metafísica da intuição e da duração. (Bachelard, 2007)
} 
fenomenólogo aponta, é ato de uma superposição temporal, de um ser pleno no tempo. Através dos instantes, e desta superposição dos instantes, é que é possível se entender a realidade dos múltiplos tempos vividos pelo sujeito. Posteriormente, as vibrações e lembranças da casa como espaço onírico nos ajudarão a entender melhor o projeto do IAPI.

Aportado em uma sólida base de análise teórica, Leandro Marino Vieira Andrade, em sua dissertação de mestrado (Andrade, 1993), mostra que o projeto da cidade-jardim proposto pelo inglês Ebenezer Howard se inscreve em um paradigma culturalista, que se caracteriza pela acentuada crítica a cidade industrial e à pressão desintegradora dos valores sociais provocada pela industrialização. Há uma intermediação entre os espaços públicos e privados, onde o quarteirão desapega-se do sistema viário dos loteamentos tradicionais em grade; o projeto também permite que espaços de recreio fossem incorporados aos mais simples projetos habitacionais.

Segundo a interpretação de Andrade, a cidade-jardim já é em si uma superação de contradições históricas e um projeto de ruptura com o projeto de urbanização vigente na cidade de Porto Alegre. Primeiro, porque esta tradição culturalista em que estava apoiando-se Howard propõe uma nova célula dentro de uma organização mais complexa, e busca a fusão entre as qualidades positivas do campo e da cidade, entre a qualidade e ubiqüidade das vantagens urbanas, somadas ao espraiamento "saudável" do ambiente natural (Andrade, 1993: 72.). Segundo, porque na década de 40, época em que foi pensado e aplicado o projeto, a proposta vigente para o planejamento da cidade de Porto Alegre se baseava em idéias progressistas, através de nomes importantes como Edvaldo Pereira Paiva, Ubatuba de Farias e Demétrio Ribeiro. Este paradigma via a cidade através de uma outra idéia de conjunto, muito menos sistêmica e muito mais dependente de uma centralidade governamental ${ }^{10}$.

Em Porto Alegre, o projeto do eng. Eduardo Gardolinski tenta, como mostram alguns textos, trazer para dentro de Porto Alegre a idéia de um espaço habitado de uma forma diferente das vilas industriais inglesas, ao mesmo tempo que contempla o valortrabalho para definir quem são as pessoas ou sujeitos que fazem este lugar existir:

A casa deve refletir as características e tendências do homem e da família, de modo a servir suas necessidades e possibilitar o desenvoltimento de uma vida são

\footnotetext{
10 É possivel identificar, na dissertação de Andrade, uma preocupação em também tentar mediar um projeto e uma escolha individual do eng. Responsável pelo projeto do IAPI e as condições sociais mais amplas que eram colocadas através das políticas de habitação e trabalho do governo getulista.
} 
e intergral. Da mesma forma, o urbanismo deve orientar-se no sentido de planejar a edificação das cidade, tendo em vista satisfazer as necessidade funamentais das populações e propriciar uma convivência democrática, efetive e feliz. (...) Conquanto o ideal seja a casa individual, cuja construção merece estímulo e ajuda, circunstâncias várias da vida moderna levam à solução dos chamados Conjuntos Residenciais. Esses conjuntos, tanto quanto possível, devem refletir a necessidae da vida social, evitando a homogeneidade excessiva resultante da sua locação ou venda de elementos pertencentes a uma categoria profissional específica. (trecho do projeto inicial do eng. Eduardo Gardolinski, in SMPM, 1994)

Para Andrade, é evidente no IAPI a distinção entre espaços públicos, semipúblicos e privados, que configuram zonas de mediação entre os moradores. A contribuição da antropologia, no entanto, pode ir além deste reconhecimento, e a etnografia, além de uma "experiência estética", como considera o autor", pode problematizar e rever algumas idéias de endurecimento e patrimonialização deste espaço vivido.

Entrando em campo, pude ouvir pequenas narrativas e estórias de alguns antigos moradores sobre suas escolhas e suas impressões do bairro. Trago aqui uma pequena conversa que tive com um casal que ao me ver com a máquina fotográfica em punho, me perguntou que tipo de pesquisa estava fazendo:

O casal, de mais de 60 anos, diz que mora ali há mais de 50. Dona Nara chegou com o pai, quando tinha 9 anos, e seu Fred foi para o local após o casamento, pois era industriários da Aços Finos Piratini. Além de reclamar sobre como as pessoas modificam suas casas sem a menor preocupação com a construção original, falam de como os prédios eram todos iguais antigamente, e a pintura não variava muito. As diferenças atuais e mais marcantes se devem a intervenção dos moradores e pude, mais tarde, fotografar algumas variações de janelas, cores e portas(...) Quando pergunto sobre as condições de vida na época, me afirma que não tinha nem luz, mas também reconhece que mudaram a casa deles, devido a chegada de 3 filhos, e que dois deles ainda estão morando no local.

O cotidiano é sempre cheio de contradições. Ao mesmo tempo que defendem a "patrimonialização" do IAPI, os dois reconhecem que a vinda de filhos, enfim, as intermitências da vida cotidiana, praticamente obrigam as pessoas a mudarem suas casas, seus princípios, suas visões de mundo, seus estilos de vida, entre tantas outras coisas. Ainda querendo seguir meu trajeto fotográfico, sem intenção de incomodá-los, anoto telefone e e-mail dos dois para um possível contato. (Diário de campo dia 02 de outubro de 2010)

O que este "relato" etnográfico nos traz é extremamente intrigante para pensar estas práticas de espaço. O que é para um morador do IAPI viver neste espaço? Norteado por DeCerteu e o que ele chama de "relatos de espaço" (DeCerteau, 1994: 212) é possível se perguntar que práticas cotidianas são estas que, através de ações narrativas, realizam o sentido do ser no mundo.

\footnotetext{
${ }^{11}$ Andrade, 2007, p. 143.
} 
Re-orientar ou re-utilizar uma forma de habitação e um planejamento com o passar do tempo pode falar de uma tática, um discurso estabelecido por percursos e práticas cotidianas. A riqueza destas questões estão certamente na superação de uma dicotomia que até mesmo DeCerteau postula entre o espaço privado e público. Mesmo que este autor esteja falando de um percurso em um espaço mais público (talvez seria melhor falar em espaço compartilhado), através de uma experiência individual, a "organicidade" e o objetivo do projeto arquitetônico do IAPI também coloca uma relação direta entre estes relatos de espaço que são modificados e se modificam com a experiência no tempo.

Existe espaço sempre que se tomam em conta vetores de direção, quantidades de velocidade e a variável tempo. O espaço é um cruzamento do móveis. É de certo modo animado pelo conjunto de movimentos que aí se desdobram. Espaço é o efeito produzido pelas operações que o orientam, o circunstanciam, o temporalizam e o levam a funcionar em unidade polivalente de programas conflituais ${ }^{12}$ ou de proximidades contratuais. (DeCerteau, 1994, p. 202)

Refletindo a partir de Bachelard, podemos reconhecer estes conflitos e tensões colocadas por DeCerteau como fundamentais para a dialética do ser na morada. Ao pensar a "Poética do espaço" (1984), o autor nos coloca diante de um problema inovador e capaz de dar conta de dualismos inerentes à experiência do sujeito no tempo. Ao fazer uma fenomenologia das imagens poéticas da morada, a imagem da casa é vista como o princípio verdadeiro de integração psicológica. Para o autor

\footnotetext{
O espaço percebido pela imaginação não pode ser o espaço indiferente entregue mensuração e à reflexão geômetra. É um espaço vivido. E vivido não em sua positividade, mas com todas as parcialidades da imaginação. Em particular, quase sempre ele atrai. Concentra o ser no interior dos limites que protegem. $O$ jogo do exterior e da intimidade não é, no reino das imagens, um jogo equilibrado. (Bachelard, 1984, p.196)
}

Portanto, lidar com dualismos é também condição principal para o ser pleno da morada. Já pensando em futuras indagações para responder em outros trabalhos, é preciso pensar a condição da casa no universo, onde ao mesmo tempo, na relação com o mundo exterior, a morada pode assumir valores de negatividade e positividade. A tentativa de trabalhar com as idéias de interior e exterior, público/privado, é muito mais uma tentativa de superar as dicotomias através das tensões e da memória, do que estabelecer um estatuto ou valor para os termos do projeto e da idéia do conjunto habitacional do IAPI. Como ensina Bachelard, há uma dialética do aberto e do fechado,

\footnotetext{
${ }^{12}$ Grifo meu.
} 
do interior e do exterior, que vai além do concreto ou da geometria dura, repousa na imaginação e na poética da experiência do espaço no tempo.

Partindo destes princípios epistemológicos, o desafio que se coloca em campo agora é o trabalho com narrativas. Seguindo os argumentos de Eckert e Rocha (2005), o "tempo social" é o produto da consolidação deste tempo através de uma comunidade, "fruto de uma hierarquização de uma séria de instantes e de rupturas de trajetórias vividas" (2005: 90). Há além da grande influência bachelardiana da duração, o princípio de pensar as narrativas sob o olhar de Paul Ricoeur (1994). O filósofo francês afirma que o ato de narrar é que dá sentido ao caráter temporal da experiência humana.

(...)o tempo torna-se tempo humano na medida em que é articulado de um modo narrativo, e que a narrativa atinge seu pleno significado quando se torna uma condição de existência temporal(...)(1994: pp.85)

Sempre tendo cuidado com o termo "sentido pleno" da narrativa, podemos considerar a obra de Ricoeur importantíssima para os estudos sobre narrativa e rememoração. Tendo como base a releitura descrita por Eckert e Rocha (2000) a partir de Durand e Bachelard, a "inteligência narrativa" proposta por Ricoeur argumenta que o tempo vivido é tornado "humano" porque acomoda as lacunas e ondulações deste tempo, impensáveis para o pensamento racional pós-Iluminismo. $\mathrm{O}$ ato de narrar envolve, além da simples rememoração do passado, outras diferentes etapas, em que o pensamento organiza o presente e dá sentido a uma série de acontecimentos, e dá à união de diferentes acontecimentos, um tema, uma história, um argumento ${ }^{13}$.

\section{Desafios futuros, à guisa de conclusão}

Estar diante do fenômeno do tempo nas sociedades complexas é sempre um desafio renovador. Este artigo tentou, de forma ainda introdutória, buscar pontos de ancoragem e reflexão para lidar com um caso específico de habitação popular das classes operárias no mundo urbano-contemporâneo. Se estamos aqui diante do fenômeno do tempo nas sociedades complexas, é preciso se perguntar como a prática etnográfica e a produção de conhecimento na antropologia podem contribuir para

13 Segundo Paul Ricoeur estas três etapas são denominadas de Mimese I, II e II. A mimese primeira, da pré-figuração do tempo, exige do narrador a pré-compreensão do mundo e da ação, suas estruturas inteligíveis, as suas fontes simbólicas e seu caráter temporal. A segunda mimese, do tempo figurado, configura a narrativa através do agenciamento dos fatos e através da poética, coloca os fatos em uma história de ordem cronológica através de episódios dispostos em um certo sentido. A terceira e última mimese é a do tempo re-figurado, que conclui o processo cíclico de compreender este tempo humanizado. 
questões da vida cotidiana que revelem algo mais além de um discurso pronto ou idealizado sobre a cidade. Adentrar no agenciamento de uma memória coletiva é adentrar nos jogos da memória que estão sendo postos em dinâmica, modificando e sendo modificados pelas tensões comuns da urbe e da interação de seus habitantes.

Olha para o IAPI através destas lentes é olhar para as práticas cotidianas, para o ritmo da vida vivida em seus pormenores, nas artes de fazer, nos enunciados narrativos da memória e nas formas de sociabilidade dos seus moradores e habitués.

Por fim, cabe ainda salientar que é preciso desvincular, ou tomar cuidado para traçar com clareza os limites do trabalho do antropólogo e da visão de um assistente social ou jornalista pronto para fazer denúncia pela voz dos interlocutores, como destaca Teresa Caldeira (1981). Em minhas primeiras experiências de campo, já pude perceber a indignação de alguns destes moradores para com a prefeitura e o descaso desta no que tange aos cuidados com o bairro e as moradias locais. Há, evidentemente na cidade, uma preocupação muito grande com os equipamentos de mobilidade e a segurança pública, que muitas vezes são explicitadas para o antropólogo, na esperança de que alguns destes problemas possam ter algum dia solução.

Mesmo longe da alegoria pastoral descrita por James Clifford (1999), é preciso entender que de uma certa maneira a Antropologia é uma disciplina que se preocupa com a condição de vida de seus interlocutores. $\mathrm{O}$ desafio da pesquisa na cidade aparece assim por um outro viés, que precisa estabelecer um equilíbrio e uma mediação entre os problemas sociais evidentes em campo e a produção de conhecimento para os seus pares.

Para isso, tomo como desafio agora o estreitamento dos laços com as principais redes que começo a construir em campo, e dar voz às narrativas destes moradores. Através destes cuidados epistemológicos e a superação de alguns obstáculos, tentarei diálogar com estes diferentes campos de significados e projetos que estão colocados no IAPI, seja através de políticas públicas de patrimônio, seja através de projetos individuais e narrativas destes habitantes da cidade. 


\section{Referências:}

ANDRADE, Leandro Marino Vieira. A Estrutura de Áreas Residenciais e a Ideologia Projetual: dois paradigmas em discussão. Dissertação de mestrado, PROPUR, UFRGS, 1993.

BACHELARD, Gastón. A dialética da duração. São Paulo: Ática, 1988.

BACHELARD, Gastón. A intuição do instante. Campinas, São Paulo: Verus Editora, 2007.

BACHELARD, Gastón. "A poética do espaço”. In: Coleção Os Pensadores. São Paulo: Abril Cultural, 1984.

BARBOSA, Letícia Maria. As relações topofílicas da Vila do IAPI em Porto Alegre. Dissertação de Mestrado - Universidade Federal do Rio Grande do Sul. Instituto de Geociências. Programa de Pós-Graduação em Geografia, UFRGS, 2008.

CALDEIRA, Teresa. "Uma incursão pelo lado 'não respeitável' da pesquisa de campo". In: Ciências Sociais Hoje, 1. Trabalho e cultura no Brasil. Recife, Brasília: CNPq ANPOCS, 1981.

CARDOSO, Ruth. A aventura antropológica. Rio de Janeiro: Paz e Terra, 1986.

CLIFFORD, James. A experiência etnográfica. Rio de Janeiro: UFRJ, 1999.

DE CERTEAU, Michel. A invenção do cotidiano: artes de fazer. Petrópolis: Vozes, 1994.

DIAS DUARTE, Luiz Fernando. "A construção social da pessoa moderna" In: Da vida nervosa nas classes trabalhadoras urbanas. Rio de Janeiro: Jorge Zahar Editor/Cnpq, 1986.

DURHAM, Eunice. A caminho da cidade. São Paulo: Perspectiva, 1978.

ECKERT, C.; ROCHA, A. L. C. "O antropólogo na figura do narrador". In: Revista Habitus, v. 1, n. 2. Goiânia: Instituto Goiano de Pré-História e Antropologia/ Universidade Católica de Goiás, 2004. p. 395-420.

ECKERT, C.; ROCHA, A. L. C. "A memória como espaço fantástico”. In: Iluminuras, ano 1, n. 2. Porto Alegre: BIEV/UFRGS, 2000.

ECKERT, Cornelia; ROCHA, Ana Luiza Carvalho da. "Etnografia de Rua: Estudo de Antropologia Urbana". In: Revista RUA, março 2003, n.9. Campinhas: Núcleo de Desenvolvimento da Criatividade da Unicamp/NUDECRI, 2003. p. 101-127.

ECKERT, Cornelia; ROCHA, Ana Luiza Carvalho da. "A memória como espaço fantástico". In: Iluminuras, ano 1, n. 2. Porto Alegre: BIEV/UFRGS, 2000.

ECKERT, Cornelia; ROCHA, Ana Luiza Carvalho da. Tempo e Cidade. Porto Alegre: Ed. da UFRGS, 2005.

NUNES, Marion Kruse. Memória dos Bairros: Vila do IAPI. Porto Alegre: Prefeitura de Porto Alegre/ Secretaria Municipal de Cultura, 1991.

OLIVEN, Ruben George. "Por uma Antropologia em Cidades Brasileiras". In: VELHO, Gilberto (coord). O desafio da cidade. Novas perspectivas da Antropologia Brasileira. Rio de Janeiro: Campus, 1980. p. 23-36.

RICOEUR, Paul. Tempo e Narrativa, Tomo I. Campinas: Papirus, 1994.

SALEM, Tania. "A despossessão subjetiva": dos paradoxos do individualismo". In: Revista Brasileira de Ciências Sociais, Anpocs 18 Relume Dumara, ano 7, fevereiro de 1992.

SILVA, Cleusa Terezinha; et al. "A Vila Do Iapi No Contexto De Urbanização e Industrialização”. In: Revista do Historiador, n. 2, ano 02. Porto Alegre: FAPA, 1999.

SMPM. Vila do IAPI, Patrimônio cultural da cidade. Porto Alegre: Secretaria do Planejamento Municipal, Prefeituta de Porto Alegre, 1994. 
SOUZA, Célia Ferraz de Souza. Um resgate da cidade jardim: A Vila do IAPI. Trabalho apresentado no $3^{\circ}$ Seminário de História da Cidade e Urbanismo. São Carlos, SP. 2004.

VELHO, Gilberto. Individualismo e Cultura: Notas para uma Antropologia das Sociedades Complexas. Rio de Janeiro: Jorge Zahar, 2004.

Recebido em: 21/12/2010

Aprovado em: 28/03/2011 